\title{
Biological Communication Behavior through Information Technology Implementation in Learning Accelerated
}

\author{
Deni Darmawan \\ Department of Educational Technology, Indonesia University of Education, Bandung, Indonesia \\ Email: diestry2005@yahoo.com
}

Received February 2, 2012; revised June 5, 2012; accepted June 25, 2012

\begin{abstract}
The Biological Communication Behavior of the Left and the Right Brains have been constructed through the explanation of the phenomena of their specific part activities encompassing: Prefrontal, Frontal, Parietal, Central, Occipital and Parasagital which have been significantly tested in terms of their impacts in learning acceleration starting from Elementary School to University levels. This study is conducted by means of constructive approach and it employs both the quantitative and qualitative techniques. The result of the study shows that the biological communication of the left and the right brains are reliably tested scientifically from the viewpoint of science. The Problem Based Learning start from elementary school to university level of both social and science groups.
\end{abstract}

Keywords: Biological Communication; ICT; Learning Accelerated

\section{Introduction}

According to the observations of the real phenomena at multiple levels of educational institutions ranging from Elementary School to University shows the development and adoption of information and communication technology aspects are still obtained different from its abilities and results. The result shows the utilization and design of technology-based learning is not accompanied by information and communication and inappropriate with the results of research on the empowerment of learners' learning ability. Looking at the phenomenon in Bandung city, there are many educational institutions that already have the infrastructure of information and communication technology (ICT) and they should be able to provide support for the innovation of education and modern learning, but in fact it has not been optimal [1]. This phenomenon occurs as in Al-Biruni Elementary School, Laboratory School UPI, Pilot School of Education of West Java Province, Mutthohari Junior/Senior High School, Junior High School 2 Bandung and Junior High School 2 Cileunyi [2].

Similarly, in the university level as Curriculum and Educational Technology discipline at Indonesia University of Education (UPI), all adoption and innovation of information and communication technologies to improve the quality of learning for students, but until the recent time the results have not been optimal. This problem is not recognized by teachers who also had never noticed on the biological aspects of brain learners respectively
[3]. This condition occurred because the teacher knows the properties of left and right brains only, but they do not understand how the behavior of the brain that makes the process of communication between the specifically parts to work when the students are learning (Reliability Testing Interview Guide Supporting Curricular Activities in the Framework of Implementation of Competency Based Curriculum (CBC), Directorate General for Basic and Secondary Education, December 2003) [4].

Biological communication processes in the human body is controlled by the brain to produce certain behaviors as described by the experts, then become a basic in the process of reviewing the biological communication behavior of an individual. Based on the explanation above, this study aimed to find out the process of communication through biological behavior of biological communication left and right brains that happens to the students (learners) in the implementation of information technology that is able to support accelerated learning, as described by [5] Darmawan, in his research entitled "Lateral Acceleration Computer Based Tutorials in Learning Mathematics”. Furthermore, in order to obtain data regarding the validity of the findings about the biological behavior of this communication, the proof is carried out based on his review of Communication, Psychology, Education, Medicine or Biology, and Information Technology science perspective based on experts who has capability in that field. Thus the scientific collaboration among the biological communication, information and communication technologies in education and learning 
process is able to answer the public's expectations about the quality of learning.

Kadir and Triwahyuni [6] in their book said: "Information technology is a technology that combines computing (computer) with high-speed communication lines that carry out data, voice, and video.” The definition can be explained that information technology envisages that either implicitly or explicitly not only in computer technology, but also in telecommunication technology. Some IT-based learning model that is assumed to be able to serve the learning needs of students in accordance with the conditions and the biological communication behavior in the brain is a computer-based learning that among others includes 1) model training (drills), which is to train the memory; 2) the tutorial model, which is to guide independent learning; 3) the simulation model, which is to train and sharpen the sense of understanding; and 4) model games, which is to train the tendency to act, Darmawan [7]. The fourth models of learning are assumed to be influenced by the biological communication behavior that occurs in the brain of each learner as they do learning activities [8].

Biologically, behaviors that occur in a person are actually influenced by the work of the structural genes that control the polypeptides in the body. This process affects the size of the enzyme that is produced and controlled by regulator genes in the body. So the regulator genes are the receiver that transform dose of enzyme production. Dose of enzyme produced when the individual is pregnant, which puberty influence the psychological forms of behavior that is different from normal. This biological phenomenon can be used as the basis how interpersonal communication process that must be conditioned or unconditioned based on these genetic factors. The author assumes that the genetic information of individuals is informed of the next one to the individual and from generation to generation. It associated with the process of cultural transformation that is influenced by biological conditions on the phase transformation of cultural messages between individuals with another. This phenomenon becomes a special study of sociobiology, where according to Cavaaly-Sforza [9]; it will lead to the study of biological and cultural orientation in a unified explanation. The progress expected can answer the fused evolutionary, in which cultural phenomena are combined with biological removal.

Basically, humans have a biological system that regulates the process of communication between the networks controlled by the brain (limbic system). [10] Geoffrey explained: "This system controls the communication process between the brain network functions that relate with kinds of behavior such as angry, sad, happy, emotion, thirsty and hunger, etc. In a first step in expressing complex of all biological systems of the condition of the network expanded its communication by the language setting that is controlled by the enlargement of the neocortex [2]. In other biological phenomena are assumed as a biological pattern of communication, such as blood pressure, breathing, and awareness levels are controlled by the neocortex of these frontal and temporal. The ability of neocortex can also be felt in other brain functions such as planning, memorizing and speaking.” Biological behavior of the phenomenon of communication mentioned above if properly recognized by teachers and students when learning utilizing IT in the learning model is expected to support the process of accelerated learning [2].

Based on the rationale above, the problems of the study is focused on "How does the biological communication behavior that occurs in the learners' brain when doing activities to observe, to feel, to understand, and the tendency to act before and after obtaining information on Information Technology-based learning education in primary, secondary and higher education level in the field of exact and social sciences?”

\section{Research Methodology}

\subsection{Rationale}

The study was conducted using a quasi and laboratory experiments and explanatory survey. The idea of combining these methods is referring to especially based on the data category [11]. Interval is for quantitative category and ordinal is for qualitative category. The other reasons of the combined use are: first, providing a new experience in research related to education and learning process which tends much to do with quantitative approaches, experiments, researches and developments [12]. Second, trying to do the analysis from two different viewpoints, but it is intended to crosscheck methodologically for examining the phenomenon that is expected to answer the identification problem that is formulated that will assist researchers in interpreting the overall findings in the field both quantitatively and qualitatively. The focus of this study is to obtain subjective descriptions of the biological communication phenomenon that used Electroencephalography (EEG) [13]. EEG is used to describe the biological communication processes between left and right brains that occurred to the subject under study as the informants.

Visually, the application of two research approaches above can be seen in the following procedures:

Based on phases I and II above (Figure 1), the qualitative method proposed by Deddy Mulyana [14] was used to find the answers to the phenomenon of biological communication by using several instruments such as in-depth interview, observation, and FGD. Next, data was analysed using data analysis guidelines as proposed 


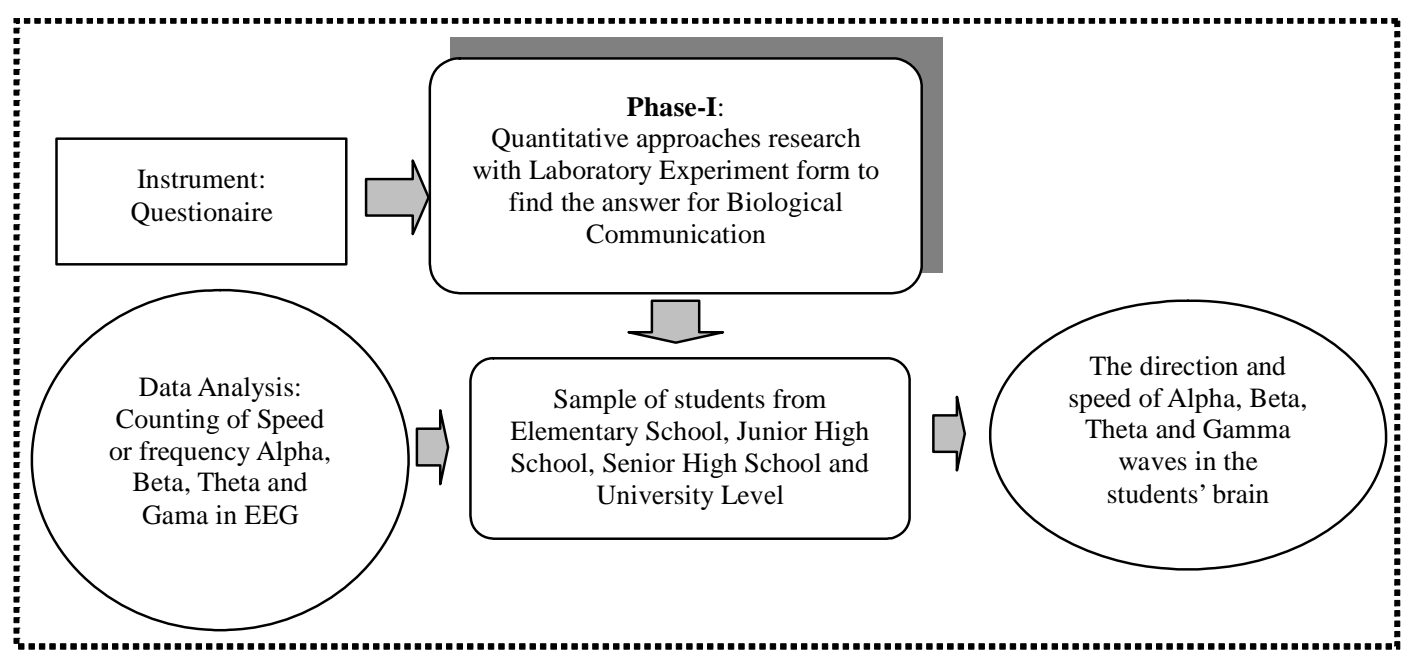

(a)

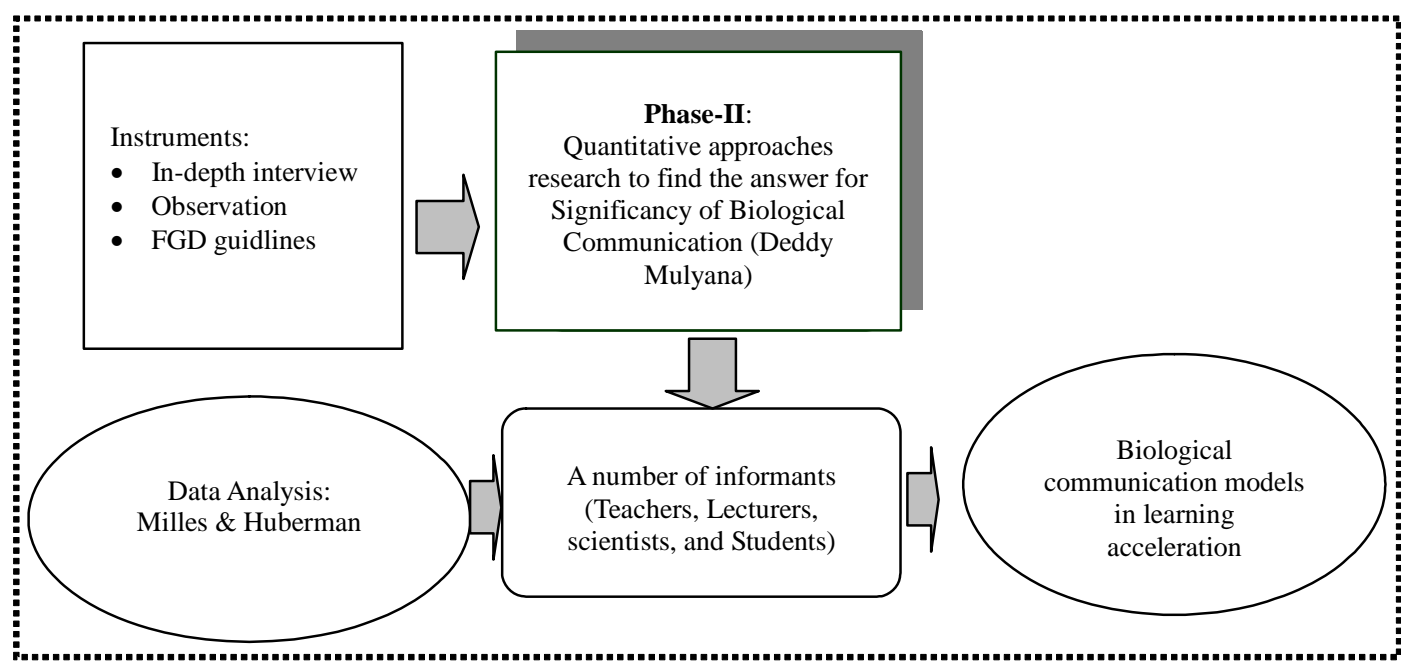

(b)

Figure 1. Quantitative and qualitative approaches research.

by Milles \& Huberman which consist of 1) Data Collection; 2) Data Reduction; 3) Data Presentation; 4) Conclusion and verifications. After going through all the four stages of data analysis, data then was validated by teachers, lecturers, and students from elementary through university levels. The final result of these processes was the finding about biological communication models in accellerated learning.

\subsection{Data Sources and Informants}

Data sources in this study are set based on basic education to university level and scientific experts in Bandung city. The infomants are the experts from education, communication, psychology, medicine, culture, and information and communications technology. Special for the implementation of the EEG examination, two students from each level of education that have been implementing information technology-based learning and commu- nication are selected. The total number of sample is eight students. Determination of four students to the EEG lab is done based on expert decision of researchers and neurologists of the limitations of the use of tools, time, and EEG examination procedures. The informants in this study using expert informants of Education Technology, IT Specialists, Medical Specialists, Communications Specialists and Biology expert.

\subsection{Data Collection Techniques and Data Analysis}

As disclosed above that the data collection techniques used in quantitative approaches include:

1) Guidelines for Examination of EEG Test Results

The instrument used is the EEG examination guidelines developed collaboratively with the team of researcher and Neurosurgeries from Hasan Sadikin Hospital consisting of dr. Yustiani, and Siti Aminah, under the 
direction of Kahdar [15].

2) Qualitative Data Collection Techniques

Data collection techniques used in qualitative approaches include: in-depth interviews, observations and focus group discussions.

The data is presented in words (not numbers), so that the analysis is based on words that are arranged into the form of text. Data analysis will refer to the pattern defined by Miles and Huberman [16] consisting of four flow events occurring simultaneously, these are: 1) data collection; 2) data reduction, which is the activity set of data abstraction, 3) data presentation, which is serving points or outline data validity ensured; and 4) conclusions and verifications, which conclusions drawn tentatively to be verified during the study period. Analysis of the influence of variable packaging information to learning acceleration that is controlled by biological communication is done with Path Analysis [17]. Because of the data was obtained from the ordinal scale questionnaire, it previously had to go through the process of transformation into an interval scale by using Successive Interval Method [2].

\section{Result and Discussion}

\section{The Biological Communication Behavior Process That Occurs in the Learners' Brain}

The study findings suggest that the biological communication processes that occur between the left and right brains at the students who learn using IT-based learning, both before and after learning, can be explained from the results of EEG [13].

1) Prior to the stimulus, the emerging wave is alpha $(\alpha)$ wave, as shown below (Figure 2).

As explained by Aminah [16], brain activities prior to any stimulus only show one active wave which is the alpha wave. Findings of this study support the opinion as the recording of the alpha wave activities were conducted to the sample of the study before giving any stimulus.
Figure 2 above shows that the alpha waves work only based on waking movements with eyes closed, and before they turn into beta waves.

Figure 2 shows that the wave that emerges is the beta waves that can be read on line 1 until 5 . It shows the wave occurs in specific parts of the left brain, and row 6 until 10 beta waves occur in specific parts of the right brain. The wave that has amplitude with sharp peaks and valleys (Row. 1: FP1 F7) is a beta wave that show artifacts in accordance with the activities carried out as in the figure above is the observed wave activity (which is done through the seeing motion). While the waves with flat and small amplitudes is a beta waves that really shows the activity of specific parts in processing and sending a message from a channel (specific parts) to other. The traffic of how messages flow in specific parts of the brain while an individual receives stimulus, such as stimulus received by vision senses, can be seen as visualized in Figure 3.

2) After the ICT-based stimulus, then the alpha $(\alpha)$ wave turns into beta $(\beta)$ wave, and the moving path of the information can be seen everywhere, from one specific part to another one. Waves that arise can be seen in Figure 3.

Figure 3 shows that the wave that emerges is the beta waves that can be read on line 1 until 5 . It shows the wave occurs in specific parts of the left brain, and row 6 until 10 beta waves occur in specific parts of the right brain. The wave that has amplitude with sharp peaks and valleys (Row. 1: FP1 F7) is a beta wave. It shows artifacts in accordance with the activities carried out as in the figure above is the observed wave activity (which is done through the seeing motion). While the waves with flat and small amplitudes is a beta waves that really shows the activity of specific parts of the process, send a message from the channel (specific parts) to other. While to see the message flow in the specific part of brain such as accepted stimulus through visual sensor [2] can be seen in the following Figure 4.

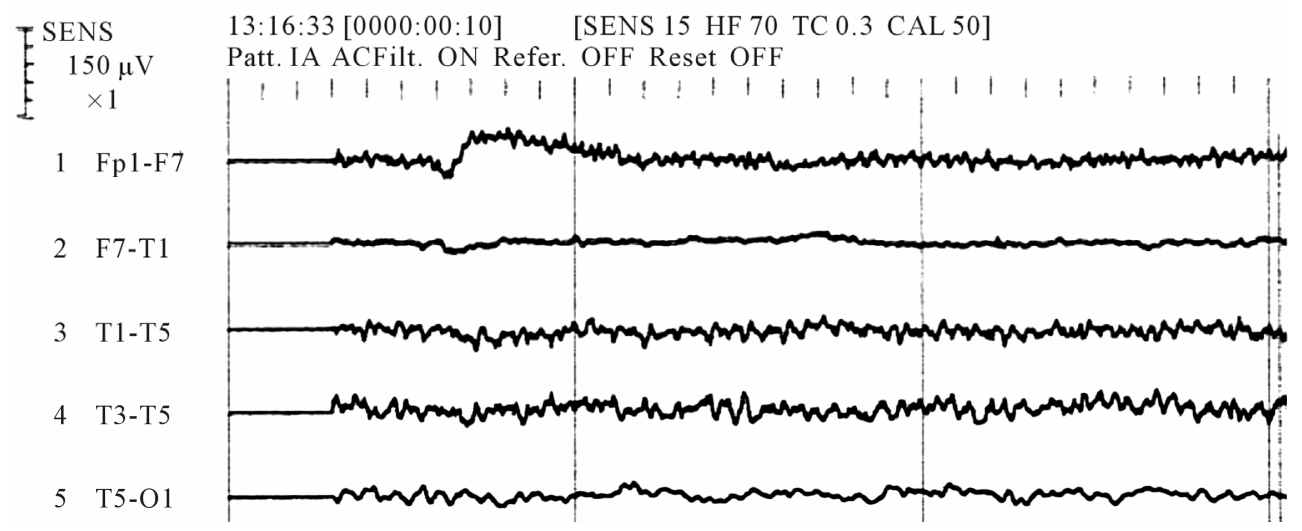

Figure 2. Alpha waves indicate brain's normal conditions prior to visual ICT-based stimulus (EEG recordings). 


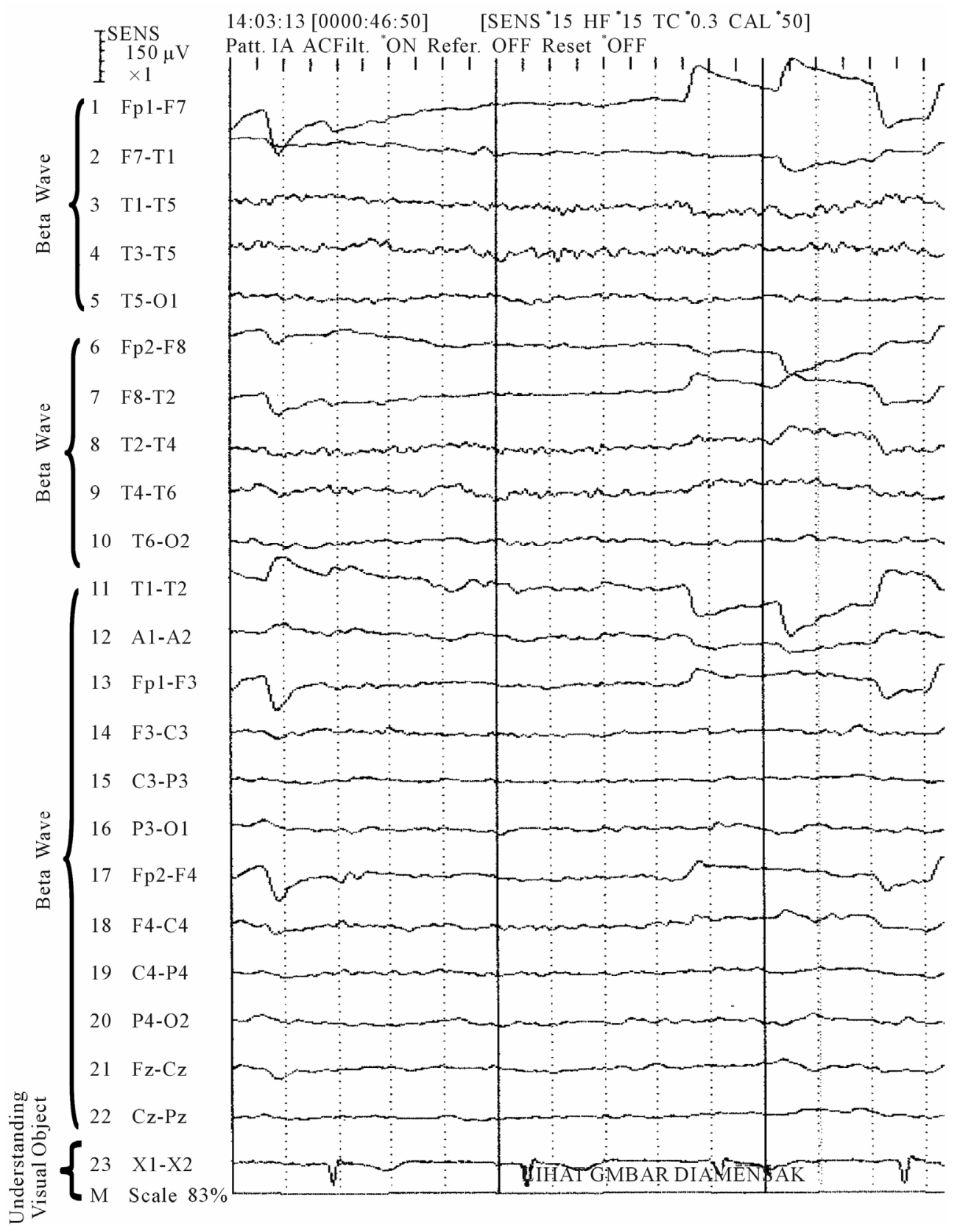

Figure 3. Alpha waves which turn into beta waves due to ICT-based stimulus through his vision (EEG recordings).

The wave line from 1 to 10 can be read anywhere in the message flow specific parts of the brain, it can be seen in the visualization (Figure 3) that indicates where the points as a channel that shows the location specific parts of the brain that consists of Prefrontal (Fp), Frontal (F), Temporal (T), Occipital (O), Parietal (P), and Central (C) and the Association (A) are scattered in the left brain which is characterized by an odd number and the right brain marked with even numbers [13]. To read the waves that arises from the EEG in relation to the picture on the start of the line wave from 1 to 5 and 6 to 10. It can be exemplified as follows:
1) The stimulus in the form of a message in visual form in and arrested by the nerves of sight and move specific parts Prefrontal (FP1) assign it to specific parts of Frontal (F7) in the left brain and (FP2) to specific parts of frontal (F8) in the right brain, appears on the display monitor EEG waves on line-1 with dynamic amplitude motion.

2) Figure 3 message continued from (FP1) to a specific section Frontal (F7) in the left brain to the specific temporal (T1) on the wave characterized by line wave number 2 is F7-T4. The same thing is occurred in the right brain, where the message of the frontal (F8) to 


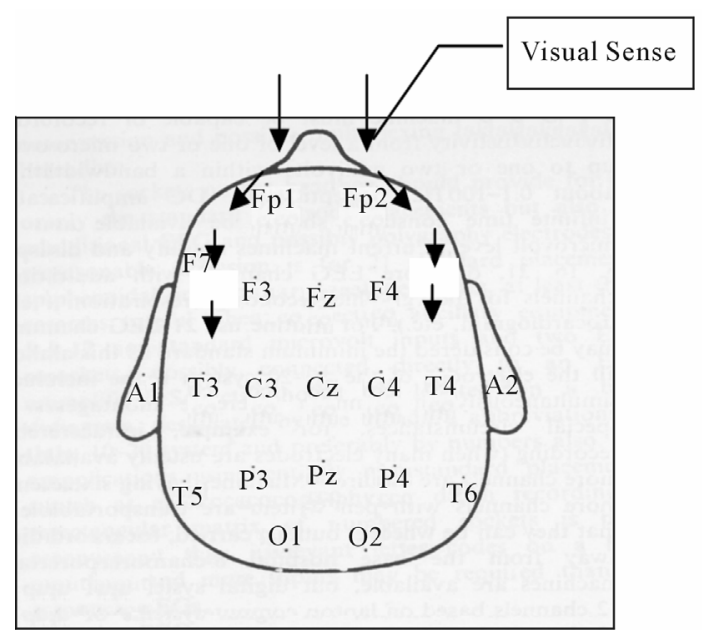

Figure 4. The specific parts location of the left and right brain for the visualization of readings (The result of EEG).

temporal (T2) is shown in line number 7 in the waves with EEG recordings.

3) Reading the wave shown the presence of pair's activity of specific part of left and right brains continued with reading a line waves number 11 to line 22. It finished at line wave 23 when the student understanding the visual object that signed by note that appears in EEG display.

Biological communication behavior process [2] occurs in this study is shown in activities when learners from Elementary School to University levels learn to observe, feel, understand and tendency to act occurs in specific parts of the left and right brains, these are: Prefrontal (Fp), Frontal (F), Temporal (T), Parietal (P), Central (C); Occipital (O); and Parasagital (FCP) [13]. Alpha and Beta waves velocity are different in receiving, processing and transforming both the message of learning the exact or social groups before or during the learning based on information and communication technology [18].

As additional findings of this study, the researcher can explain several biological communication activities that occur while an individual performs activities such as seeing, tasting, thinking, and acting. Those biological communication activities can be explained through activities of specific parts of the brain. The explanation is as follow:

1) Biological Communication Behavior activity when "seeing".

From Figure 5 can be seen that the biological communications behavior made by the senses of sight. It shows that the message coming through the left eye passed to the brain as a cross section that is specific to the right and the message received by the right eye forwarded to specific parts of the left brain. These findings can be applied in an effort to assist students so that they can gain optimal learning in the process of observing

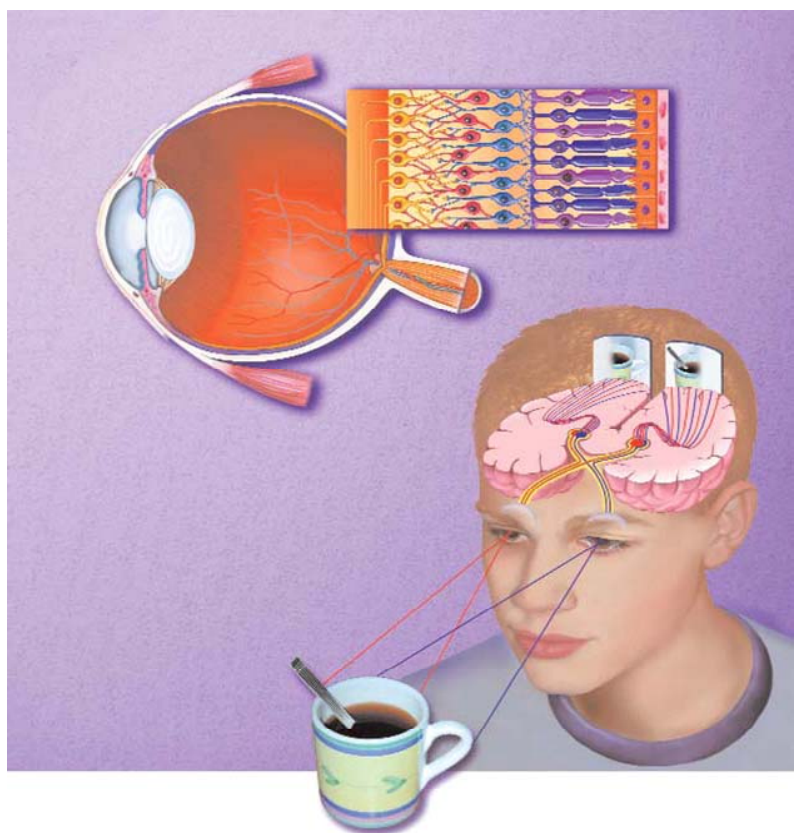

Figure 5. How do Occipital receive information stimuli from visual sensory for "seeing".

learning messages given by the teacher while they perform fast learning activities (acceleration) in the form of learning through visual observation [3].

2) Biological communication behavior activity when "feeling".

The Figure 6 shows that the biological communication behavior that occurs when students are learning can be explained by the state of "feeling" or sense something processed by specific brain sections derived from the processing of stimulus-based IT learning messages that are processed by the occipital and then later in the auxiliary by other specific parts of the brain that is the temporal, frontal and parietal [2]. It will be resulted in the phenomenon that the message is important to consciously perceived by the students. This finding also supports the successful accelerated learning [19] because students feel that the message is indeed necessary.

3) Biological communication behavior activity when "understanding".

Communication of findings on the biological behavior of the previous figure can be seen how the application in a process of learning activity when students have to understand the teachers described the learning message. It can be described starting from the activity before and during stimulus obtain IT-based messages. Before obtaining the behavior of biological stimulus of communication that occurs in the brain learners performed by frontal, temporal, occipital and parietal [13] is located in the left and right hemispheres assisted Central, Parasagital and Hypocampus. While there is a stimulus during the working process is assisted by the cerebellum so that all 
the specific parts of the brain work in a balanced and equitable. Further this psychological motivation (motivetion to learn) which is further supported by the flow of blood from the brain as a command to the members of the body such as hands to perform learning activities such as typing, as shown above (Figure 7) or pay attention to the teacher explaining the material in front of the class [20]. So the findings could help students' learning

\section{accelerating.}

Shahib [20] explained, "Individual learning accelerated is influenced by blood condition in the brain, which is the active blood will support the speed of the individual in accepting the information."

4) Biological communication behavior activity when performing a tendency "acting".

Figure 8 shows that the tendency to act that happened

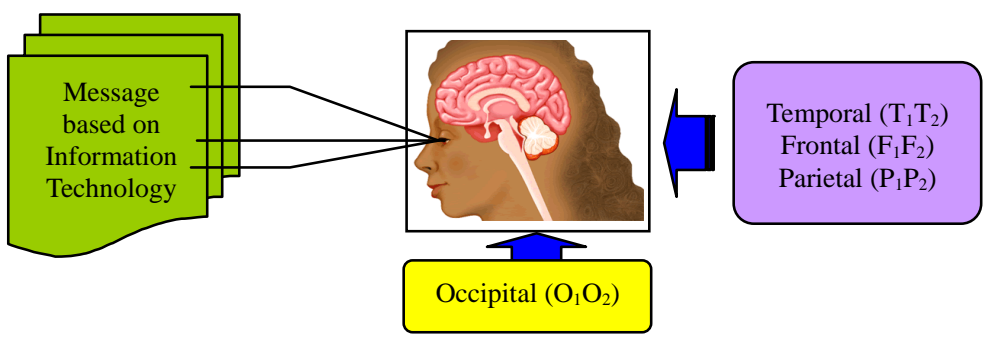

Figure 6. Biological communication activity when "feeling”.

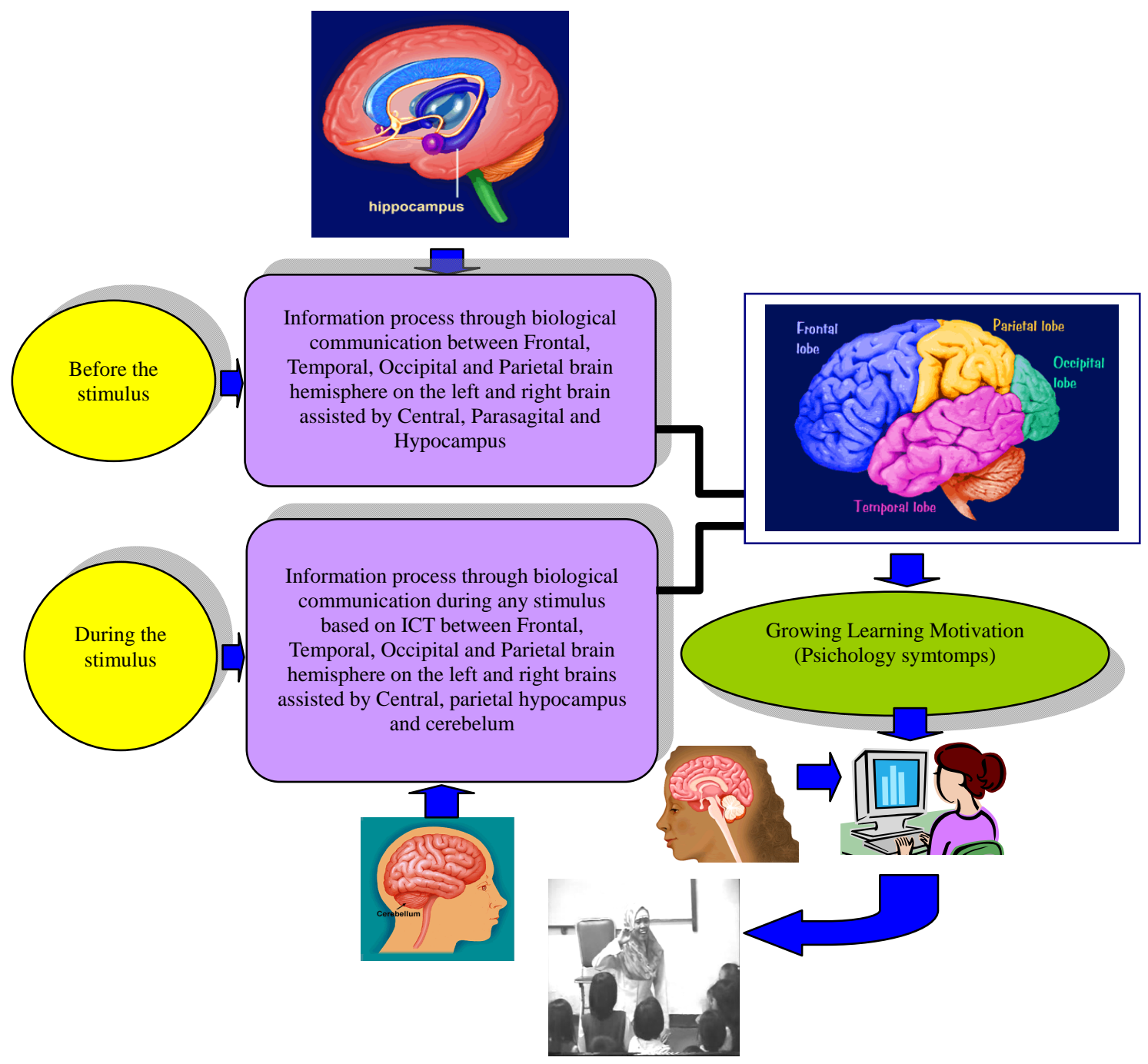

Figure 7. Information processing models of biological processes involving communication based on the presence or absence of a stimulus-based information and communication technology in the form of activity "understanding". 


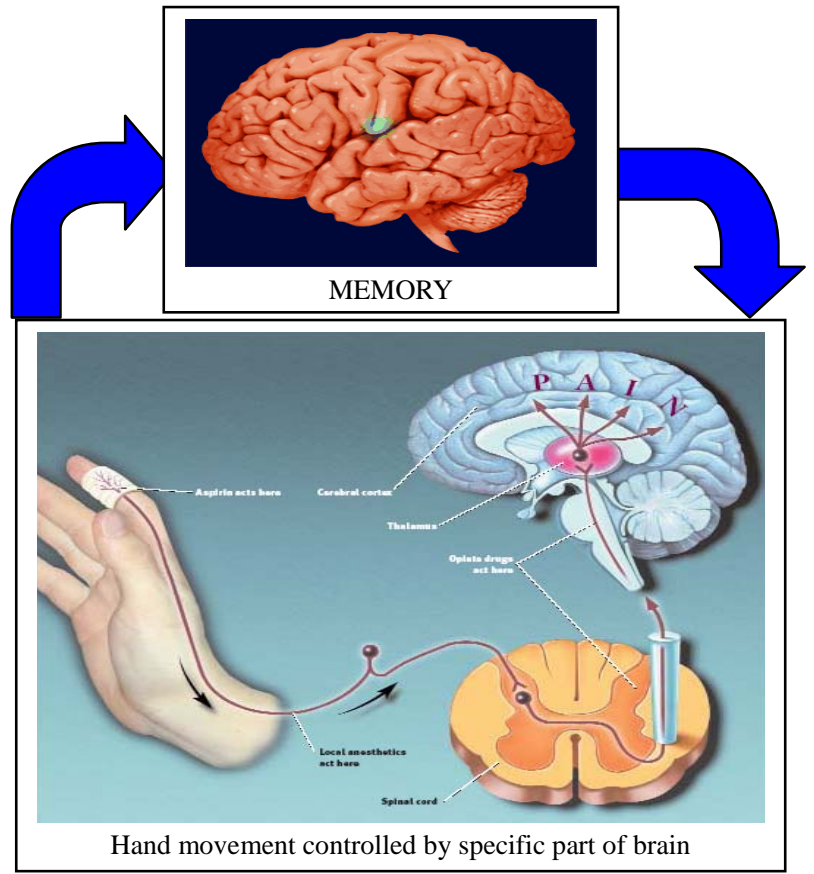

Figure 8. Biological communication behavior activity when performing a tendency "acting”.

to students are basically very complex influenced by previous information that resides in memory [21]. A new movement that carried out by members of other bodies will also be incorporated into the memory as an input. These findings suggest that the biological communication behavior in the form of these tendencies can be said to be a cycle of limb movements resulted based on commands from the brain which then results are recorded and relayed back to the memory in the brain [22]. If this phenomenon occurs tendency to reflex action would enhance a student learn faster remedy of specific movements from simple to complex. This finding is appropriate with Piaget's explanation about the basis of human intelligence and biological organism [23].

\section{Conclusion}

This research obtained two strategic and important formulations in the proof of biological communication behavior based on the accelerated implementation of IT in supporting students' learning. Biological communication behavior can be found in specific activities of the brain during observing, feeling, understanding and acting ongoing performed by the prefrontal, frontal, parietal, temporal, parasagital, central and occipital thoroughly with different speeds in the hemispheres of the left and right brains. These findings occurred both before and after receiving information-based learning information technology, especially in transactional as a form of interaction between cells in the brain that are reviewed on a biological communication perspective.

\section{REFERENCES}

[1] Republic of Indonesia Ministry of National Education, "Development of ICT Policy in Indonesia," 2011.

[2] D. Darmawan, "Learning Communication,” Humaniora, Bandung, 2007.

[3] E. Jensen, "Brain Based Learning,” The Brain Store, San Diego, 2003.

[4] Basic Education Project, "Monitoring and Evaluation Program,” Educational Ministry of Province, West Java, 2003.

[5] D. Darmawan, "Classroom Action Research: Lateral Acceleration Computer Based Tutorials in Learning Mathematics," Institute for Research Cooperation with Indonesia University of Education, Ministry of Higher Education, London, 2003, p. 55.

[6] A. Kadir and T. C. Triwahyuni, "Introduction to Information Technology,” Yogyakarta Andi Publisher, Yogyakarta, 2003.

[7] D. Darmawan, "Information and Communication Technology,” Arum Mandiri Press, Bandung, 2007.

[8] S. M. Allesi and S. R. Trollip, "Computer Based Instruction,” Prentice Hall Inc., Englewood Cliffs, 1984.

[9] W. B. John, H. Poortinga, M. H. Segall and P. R. Dasen, "Cross-Cultural Psychology,” Scholastic, New York, 1999.

[10] G. Pope, “Biological Anthropology,” Eagle, New York, 1984.

[11] J. Brannen, "Guiding Qualitative and Quantitative Research,” UI, Jakarta, 1997.

[12] M. D. Gall and R. W. Borg, "Operations Research in Education,” McMillan, Inc., New York, 2003.

[13] E. Niedermeyer and F. L. da Silva, "Electroencephalography: Basic Principles, Clinical Applications, and Related Fields,” Williams \& Wilkins A. Waverly Company, Baltimore, 1993.

[14] D. Mulyana, “Qualitative Research Methodology,” 2nd Edition, Teen Rosdakarya, Bandung, 2002.

[15] S. A. Yustiani, "Kahdar Based on Discussion about EEG,” 2005.

[16] M. B. Milles and A. M. Huberman, "Qualitative Data Analysis,” Rineka Copyright, Jakarta, 1992, p. 20.

[17] C. C. Li, "Path Analysis-A Primer," The Boxwood Press, Pacific Grove, 1975.

[18] C. Rose and M. J. Nicholl, “Accelerated Learning for the 21st Century,” Del Publishing, Inc., New York, 1997.

[19] S. Nurhalim, "Fostering Creativity towards a Global Era," Alumni, Bandung, 2003.

[20] N. W. Sham, “Tree Reconstruction Perspective Communication Studies Communication and Development Communication Paradigm Shift in Era of Globalization,” Inauguration Speech Communication, FIKOM Padjadjaran University, Bandung, 2001.

[21] R. Jalalludin, “Intelligent Learning,” Brain-Muthahari 
Press, Bandung, 2003.

[22] Fajar, “Learning Theory,” PGSD UNY., Semarang, 2012, p. 14.
[23] D. Klahr and J. G. Wallace, “Cognitive Development,” Lawrence Erlbaum Associates Publishers, Mahwah, 1976, pp. 189-223. 